\title{
INSTITUIÇÕES E PROPRIEDADE INTELECTUAL: UMA ABORDAGEM INTERDISCIPLINAR
}

Ana Maria Nunes Gimenez

Resumo: O artigo representa uma tentativa de correlacionar os conceitos econômico e jurídico de instituições e de propriedade, com o objetivo de estender a aplicação desses conceitos, também, à propriedade intelectual. O referencial teórico procurou enfocar o papel das instituições como as instâncias reguladoras da sociedade e mitigadoras das condutas oportunistas. O que se pretendeu foi colocar em evidência o papel das instituições, vistas como estruturas que ancoram e garantem as relações sociais, econômicas ou não, e dos direitos da propriedade intelectual, como instrumentos que garantem a apropriação jurídica e possibilitam relativa segurança na determinação de estratégias para a apropriação econômica, criando uma interface entre direito e economia.

Palavras-chave: Instituições. Direito de Propriedade. Propriedade Intelectual.

\begin{abstract}
The article is an attempt to correlate the economic and legal concepts of institutions and property, in order to extend the application of these concepts, too, to intellectual property. The theoretical framework sought to focus on the role of institutions such as regulators of society and mitigation of opportunistic behavior. What was intended was to highlight the role of institutions , seen as structures that anchor and ensure the social, economic or not, and the rights of intellectual property, as instruments to ensure the legal ownership and enable relative safety in determining strategies to economic ownership, creating an interface between law and economics.
\end{abstract}

Keywords: Institutions. PropertyRights. Intellectual Property.

\section{Introdução}

Entende-se que a questão da propriedade é deveras complexa e requer um tratamento mais abrangente, ao contrário do que vem sendo dado, tanto por economistas, como por juristas, sendo

* Doutoranda e mestra em Política Científica e Tecnológica pela Universidade Estadual de Campinas (UNICAMP), advogada e docente no Centro Universitário Assunção (UNIFAI). 
recomendável a criação de um campo de estudo específico, com objeto e métodos próprios, conforme sugerem Nobre (2003) e Arida (2005). Para Esteves e Mello (2008, p. 15), devido à sua natureza, os direitos de propriedade remetem tanto a questões jurídicas, como econômicas, "e seria um objeto bastante propício ao tratamento interdisciplinar", embora seja bastante raro, pelo menos no Brasil, estudos que tratem da vertente jurídica e econômica de forma integrada (Esteves; Melo, 2008, p. 2) e ainda afirmam o seguinte:

\begin{abstract}
Entretanto, as dificuldades para o trabalho interdisciplinar em Direito e Economia são diversas: em primeiro lugar, existe uma série de diferenças entre as disciplinas - diferentes linguagens, diferentes planos de análise, diferentes prioridades, diferentes sentidos atribuídos aos mesmos termos - que precisam ser identificadas e compreendidas. Uma análise interdisciplinar deve ser capaz de superá-las - i.e., de uniformizar os conceitos analíticos utilizados e estabelecer canais de comunicação (Esteves; Melo, 2008, p. 2).
\end{abstract}

Dessa forma, partindo das constatações acima, o presente artigo representa uma tentativa de correlacionar os conceitos econômico e jurídico de instituições, com o objetivo de estender a aplicação desses conceitos, também, ao direito de propriedade e à propriedade intelectual. É importante destacar que se trata de uma discussão inicial, para demonstrar que temas cujo entendimento parecem consolidados para determinadas áreas ou disciplinas, quando transportados para outras podem suscitar entendimentos não consensuais, ou mais abrangentes. No entanto, deve-se esclarecer que, devido à complexidade da questão, não foi possível ampliar a discussão ou mesmo elaborar considerações mais detalhadas sobre aspectos específicos da área de estudo interdisciplinar que tem sido sugerida por estudiosos para explorar questões do direito e da economia. Buscou-se muito mais a identificação dos pontos de contado entre o direito e a economia que os de afastamento.

O referencial teórico procurou enfocar o papel das instituições como as instâncias reguladoras da sociedade e mitigadoras das condutas oportunistas. A abordagem jurídica sobre instituições firmou-se no referencial teórico da Teoria da Instituição ou Clássica e na Teoria Neoinstitucionalista. A abordagem econômica deu ênfase à posição da Nova Economia Institucional (NEI), em especial, ao ponto de vista de um dos seus mais ilustres representantes, Douglas North.

Trata-se, portanto, de um estudo que embora não tenha realizado uma explanação exaustiva, pretendeu colocar em evidência o papel das instituições, vistas como estruturas que ancoram e garantem as relações sociais, econômicas ou não, e dos direitos da propriedade intelectual, como instrumentos que garantem a apropriação jurídica e possibilitam relativa 
segurança na determinação de estratégias para a apropriação econômica. Nesse particular, os conceitos cunhados pela Teoria dos Custos de Transação (TCT) também auxiliaram na construção do referencial teórico, pois os direitos de propriedade criam deveres que se projetam "contra todos" e são um caminho para a minimização dos efeitos da incerteza, na atuação dos agentes econômicos.

\section{Instituições: a visão do Direito e da Economia}

Casal (1993) explica que parece existir certo consenso entre muitos estudiosos, independentemente da área do saber, que tentaram captar as definições possíveis para a palavra instituição. A investigação da essência do conceito tem revelado, ao longo do tempo, traços semânticos fundamentais, pois conduz à ideia (i) de fundação, ou seja, de algo estabelecido; e (ii) de permanência, quer dizer, de algo que reiterado, contínuo. Então, entende-se que as instituições são estabelecidas pela sociedade e perduram no tempo, conforme os interesses e valores desta mesma sociedade. Para Matthews (1986), o conceito de instituição vincula-se a diferentes eixos ou abordagens que são as seguintes: (i) direitos de propriedade; (ii) convenções; (iii) tipos de contratos; (iv) autoridade. No entanto, o autor entende que existem características comuns entre as abordagens uma vez que as instituições poderiam ser entendidas como um conjunto de direitos e obrigações que afetam a vida econômica.

$\mathrm{Na}$ terminologia jurídica o vocábulo "instituição" apresenta diversos sentidos que podem ser empregados conforme o tipo de realidade que se pretende explicar e que em nada destoam do entendimento supra. Assim, o termo instituição pode ser utilizado para indicar (i) os atos de vontade que, lastreados em autorizações pré-estabelecidas pelo ordenamento jurídico, estabelecem e personalizam determinada coisa, ou situação jurídica ${ }^{31}$; (ii) o conjunto dos órgãos representativos de um Estado; (iii) o conjunto de normas jurídicas e preceitos normativos, princípios, entre outros, que integram o ordenamento jurídico (de um Estado); (iv) os diversos tipos de pessoas jurídicas, com ou sem fins lucrativos (sociedades, associações, fundações, etc.), estatais ou não estatais, são exemplos dos outros sentidos atribuídos à palavra instituição (Silva, 2002).

\footnotetext{
${ }^{31}$ Assim, ato que torna um imóvel residencial impenhorável, ao conferir-lhe o status de bem de família, ou as disposições testamentárias, que investem determinadas pessoas na condição de herdeiros (testamentários), legatários, ou tutores, podem ser considerados exemplos desse primeiro sentido.
} 
O pensamento jurídico institucionalista surgiu no final do século XIX e foi muito influente no decorrer do século XX, principalmente na França, Itália e Alemanha, muito embora se entenda que a sua força motriz tenha se exaurindo paulatinamente, conforme explica La Torre (2010), a ponto de ser pouco conhecido, na atualidade, ou ainda pouco valorizado, sendo um assunto tratado quase que exclusivamente em textos de Filosofia ou de Teoria do Direito.

Os textos mais significativos sobre a Teoria Institucionalista Clássica do Direito são atribuídos ao francês Maurice Hauriou e ao italiano Santi Romano. Algumas teorias mais recentes, chamadas de neoinstitucionalistas estão, principalmente, ligadas aos nomes de Ota Weinberger e Neil MacCormick. Entende-se que somente com Hauriou e Romano é que a noção de instituição assume relevância explícita e específica para a Teoria do Direito (La Torre, 2006). Maurice Hauriou é reconhecido como o fundador da concepção institucionalista do direito, entendido como um fato institucional (Reale, 1972).

Dessa forma, a instituição era considerada como uma ideia de obra ou de empresa, que se realizaria e permaneceria juridicamente num ambiente social. As instituições eram de dois tipos: (i) instituições-pessoas e (ii) instituições-coisas (Hauriou, 1968). As normas (regras) também eram vistas como instituições (instituições-coisas), o Estado e outros entes, como instituições-pessoas. As autênticas e verdadeiras instituições deveriam ter forma constitucional e representativa, o que remete obrigatoriamente à necessidade do Estado de Direito (La Torre, 2006).

Santi Romano equiparava o ordenamento jurídico a uma instituição, considerando que o termo instituição serviria para designar uma forma social organizada, estável e permanente, com estrutura e vidas próprias, como o Estado, a Igreja e as associações privadas. Para Romano, o fenômeno jurídico era um fato institucional cujas características e conteúdos seriam diferentes e específicos conforme os "fins das diversas entidades" (Reale, 1972, p. 235). Então, direito e instituição se confundiam já que todo ordenamento jurídico era uma instituição e toda instituição era um ordenamento jurídico. Logo, como várias eram as instituições, vários também poderiam ser os ordenamentos jurídicos. Essa concepção representou uma ruptura com um dos principais 
dogmas do positivismo jurídico ${ }^{32}$, que é o reconhecimento do caráter único das fontes do direito, uma vez que todas elas são oriundas do Estado (La Torre, 2010). Convém mencionar que a ideia de ordenamentos jurídicos múltiplos e que não provenham do Estado não é aceita, uma vez que por ordenamento jurídico entende-se o conjunto de normas estatais dotadas de coerção, o direito posto, positivado pela autoridade competente.

O novo institucionalismo jurídico é considerado mais refinado, quando comparado ao clássico, pois também incorpora às discussões as questões cognitivas. Assim sendo, essa corrente de pensamento não reduz o direito a uma série de normas sistematizadas entre si, pois entende que a construção do conceito de direito requer que também sejam levados em consideração outros elementos, como por exemplo, o âmbito da possível atuação das normas e dos princípios da ação, dos contextos sociais que inspiraram as normas e do entendimento que se tem sobre esses fenômenos (questões cognitivas). Portanto, para MacCormick e Weinberg, ambos representantes do neoinstitucionalismo, instituição e fatos institucionais são expressões equivalentes (La Torre, 2006). MacCormick (1998) ensina que, para aqueles que se preocupam apenas com a lei, a ideia de fatos institucionais liga-se facilmente com outra ideia, qual seja, a de que o direito ocidental é formado por instituições. Ela também se conecta com o entendimento de que direito é institucional, pois é administrado por meio de instituições, como os tribunais, as assembleias legislativas, os órgãos do Ministério Público, entre outros. Esses teóricos entendem que as práticas sociais evoluem, assim como as instituições.

Segundo o neoinstitucionalismo jurídico, graças aos fatos institucionais os seres humanos têm condições de aumentar o número de fatos existentes no mundo sem que sejam aumentados, também, o número de objetos físicos. Então, é importante a compreensão de que os direitos de propriedade sobre bens tangíveis, como um pedaço de terra são tão reais quanto os direitos de propriedade sobre coisas intangíveis, como os valores mobiliários, por exemplo, e de que tantas outras coisas podem ser possuídas, sem que existam no plano físico (Maccormick, 1998), como é o caso da propriedade caso da propriedade intelectual.

\footnotetext{
${ }^{32}$ Quando se fala em positivismo jurídico, há uma tendência inicial de se pensar em Hans Kelsen, principalmente, na "Teoria Pura do Direito", obra de grande repercussão entre os juristas do Século XX e responsável pela formação e "enquadramento" dos operadores do direito, nos dogmas da doutrina juspositivista, na veneração dos códigos e diplomas legais. Além disso, buscam-se semelhanças com o positivismo de August Comte. Norberto Bobbio, muito embora reconheça certa ligação, tendo em vista que no século XIX alguns positivistas jurídicos eram também, positivistas no sentido filosófico (do termo) informa que o termo positivismo jurídico não se origina do positivismo filosófico, mas sim, da locução direito positivo, enquanto contraposta ao direito natural. Então, as codificações são o fundamento do positivismo jurídico. A partir desse contexto, portanto, que poderá ser desenvolvida toda a dogmática positivista, atrelada a onipotência da lei (BOBBIO, 2006).
} 
Reale (2009, p. 191-192) ressalta que é importante o legado deixado pelo institucionalismo jurídico (tradicional) acerca da natureza e papel das instituições, como "uma estrutura social que não oferece apenas uma configuração jurídica, mas se põe também como realidade distinta, de natureza ética, biológica, econômica, etc., tal como ocorre com a família, a propriedade, os sindicatos [...]”. Assim, as instituições podem ser tanto uma pessoa jurídica de direito privado (associações, sociedades), como de direito público, cuja instituição máxima é o Estado, assim como a família e a propriedade também são instituições.

No âmbito da Economia entende-se que "as instituições modelam o processo político influenciando o andamento da economia" (Chaves, 2008). Da mesma forma como no Direito, também existem duas escolas do institucionalismo econômico: (i) o velho institucionalismo e; (i) o novo institucionalismo. Entende-se que os trabalhos de Ronald Coase e de Douglass North, e os questionamentos levantados por outros estudiosos, como Oliver Williamson, Harold Demsetz e YoramBarzel conferiram maior legitimidade para a análise dos papéis desempenhados pelos arranjos institucionais nas decisões econômicas e de desempenho (Libecap, 1989).

Ronald Coase, ao publicar o artigo "The Nature of the Firm” (“A Natureza da Firma”) em 1937, deu início ao que se chama de Nova Economia Institucional (NEI). Douglas North, Richard Posner, Ronald Coase, Oliver Williamson, James Buchanan, Gordon Tulloc e Harold Demsetz são considerados os principais estudiosos da NEI (Chaves, 20008). Para North (1991) as instituições são restrições humanamente criadas para estruturar as interações sociais. Elas consistem em restrições informais (tabus, costumes, tradições e códigos de conduta) e em regras formais (normas - constitucionais e infraconstitucionais, direitos de propriedade). Dessa forma, ao longo da história, as instituições foram concebidas para ordenar o convívio social e reduzir a incerteza nas relações de troca, incentivando a atividade econômica. Elas evoluem, e essa evolução ocorre de uma forma que passado, presente e futuro estão ligados, num movimento em que a estrutura institucional molda a direção da mudança econômica para o crescimento, estagnação ou declínio. A NEI, segundo Williamson (2000), opera em dois níveis inter-relacionados: o ambiente institucional (ou as regras do jogo) e as instituições de governo (jogar o jogo/podendo-se entender também, como aqueles que jogam o jogo).

Para a NEI, portanto, as instituições são vistas como sistemas de incentivos nas relações de troca, e, por essa razão, se relacionam com os direitos de propriedade. Logo, quanto maior for o 
grau de definição e de garantia dos direitos de propriedade, "mais eficientes serão as instituições como sistemas de incentivos ao desenvolvimento econômico" (Mendes, 2006, p.15).

\section{Direitos de Propriedade e Propriedade Intelectual}

A propriedade já era discutida entre filósofos, estudiosos da política e juristas, muito antes dos economistas começaram a analisar suas origens e consequências. Isso porque, os direitos que com ela estão relacionados já haviam sido implicitamente entendidos pelos antigos escritores gregos e romanos. Muitos pensadores iluministas como Hume, Locke, Smith, e outros também discutiram os direitos de propriedade, e guardadas as variações nas abordagens, em termos gerais, todos entendiam os direitos de propriedade como instituições sociais fundamentais para a criação de riqueza e prevenção de conflitos. No entanto, entende-se que foi com Hobbes (1651) que a propriedade passou a ser discutida de uma forma mais reconhecível para os economistas modernos (Lueck; Miceli, 2007).

Realmente, a questão da propriedade aparece em várias passagens do Leviatã, e, embora Hobbes defendesse que toda a propriedade pertencia ao Estado, ele também entendia que o soberano poderia atribuí-la arbitrariamente aos súditos, conforme os seus próprios critérios. Portanto, a justiça e a propriedade iniciavam com a constituição do Estado, pois fora dele, diante da inexistência de um soberano, de um poder que limitasse as ações dos homens, todos teriam livre acesso aos recursos naturais, pois não existiria a noção do que é de um ou de outro, do que é justo ou injusto (Hobbes, 1651).

Essa questão parece muito similar àquela levantada por Hardin (1968), no famoso artigo publicado pela Revista Science, "The Tragedy of the Commons" ("A Tragédia dos Comuns"), pelo menos no que se refere à má utilização da propriedade comunal, no acesso aberto. Para tanto, o autor criou uma parábola, a dos fazendeiros que incluíam arbitrariamente mais e mais gado ao pasto, para explicar essa questão. Devido ao livre acesso ao pasto cada fazendeiro tenderia a se mover conforme os seus próprios interesses, acrescentando quantos animais quisesse ao seu rebanho, o que provocaria o esgotamento dos recursos. O espaço aberto, nesta parábola, não deixa de ser um "estado de guerra de todos contra todos", ou seja, entre interesses conflitantes (o exercício de direitos comuns e ilimitados de cada um dos fazendeiros), o que inevitavelmente 
levaria à ruína de todos. Portanto, embora o sistema legal da propriedade privada não seja exatamente justo, “a injustiça é preferível à ruína total”33 (Hardin, 1968, p. 1247, tradução livre).

Assim, Mello (2008, p. 2) afirma que os economistas institucionalistas "de vários matizes", têm levantado constantemente a questão do importante papel que os direitos de propriedade desempenham no processo econômico. Segundo a autora, essa relevância está "centrada nos efeitos da atribuição de direitos sobre o comportamento dos agentes econômicos e sobre o funcionamento dos mecanismos de mercado". Portanto, é essencial que os direitos de propriedade sejam bem definidos e dotados de apropriabilidade para que possam ser transacionados no mercado.

Demsetz (1967) observa que os direitos de propriedade representam uma instituição social que cria incentivos não apenas para o uso eficiente dos ativos, como também para que se invista nestes. Isso ocorre porque os direitos de propriedade afetam o comportamento econômico dos agentes, pois os incentivos vislumbrados pelo proprietário delineiam o seu poder de decisão sobre a alocação dos recursos, determinam prazos, especificam as possibilidades de uso do ativo, entre outros. No entanto, Esteves e Mello (2008, p.7) alertam que deve ser considerado o seguinte:

Os direitos de propriedade da literatura econômica incluem, além de direitos reais e obrigacionais, um outro tipo de direito que implica graus de liberdade no processo de tomada de decisões - o direito de fazer ou não fazer algo por livre opção da parte do agente. Tal direito decorre de uma regra geral de nosso sistema jurídico, segunda a qual ninguém é obrigado a fazer ou deixar de fazer alguma coisa senão em virtude de lei, e significa que, na ausência de lei ordenando algum comportamento, a liberdade de decidir é juridicamente garantida. Assim, se quisermos "traduzir" para o âmbito jurídico a expressão direitos de propriedade da literatura econômica, a noção mais próxima é a de direitos subjetivos - ou simplesmente direitos-conceituados como interesses juridicamente protegidos, aos quais corresponde um direito de ação, no sentido de poderem ser defendidos no Judiciário. Tratase de uma noção suficientemente ampla, que se adequa melhor ao sentido econômico do conceito, por comportar os mais diversos tipos de direitos; o objeto de direito pode ser variado, podendo caracterizar direitos reais ou obrigacionais, além das liberdades juridicamente garantidas.

Logo, o que a citação explicita é que não é possível realizar uma "tradução" literal dos conceitos jurídico e econômico de direito de propriedade, pois a economia inclui tanto os direitos reais quanto os obrigacionais nesse rol. Qualquer tentativa de aproximações conceituais seria mais frutífera ou (mais) bem-sucedida se utilizasse o conceito de direitos subjetivos, questão a ser explorada em trabalhos futuros.

\footnotetext{
33 "Injustice is preferable to total ruin".
} 
No entendimento de Libecap (1989), os direitos de propriedade são vistos como institutos sociais que atuam no sentido de definir ou delimitar os privilégios que o Estado outorga aos indivíduos para ativos específicos. Zylbersztajn e Sztajn (2005), citados por Esteves e Mello (2008, p. 9), “definem direitos de propriedade como relações jurídicas entre pessoas, bens e sujeitos de direitos, que excluem terceiros de sua apropriação ou apreensão. Note-seque esta definição possui viés claramente jurídico".

Ao tratar dos fundamentos de uma economia de mercado, Jacquemim e Schrans (1979, p. 13), citados por Barbosa (2009, p. 26), explicam o seguinte:

\begin{abstract}
Em geral, um bem não adquire uma utilidade econômica, ou ainda, uma coisa não se converte em bem, senão graças aos direitos que se têm sobre ela. Assim, uma certa forma de propriedade está na base das trocas. Esta propriedade confere, com efeito, um controle do bem ou do serviço, de forma que haja uma relação entre o fato de adquirir e o de dispor. Assegura a possibilidade de excluir, até certo grau, a utilização por outrem. Além disso, comporta o direito de ser transferida. Quanto mais estritos são os princípios de exclusividade e de transferência da propriedade de um bem, mais o valor comercial desse bem tenderá a subir. Em suma, o verdadeiro bem é menos a coisa do que os próprios direitos.
\end{abstract}

Finalmente, para a Teoria dos Custos de Transação (TCT) os agentes econômicos estão sujeitos a incertezas, indefinições, racionalidade limitada e condutas oportunistas. Em termos gerais, pode-se afirmar que os três primeiros elementos indicam que a decisão de ir ao mercado (negociar, contratar, etc.) é arriscado devido tanto à falta de informações, ou à parcialidade destas (racionalidade limitada), como às próprias incertas e indefinições que cercam qualquer negociação. O oportunismo, conforme explica Williamson (1987, p. 57), é “a busca pelo interesse próprio, com dolo", ou seja, os agentes econômicos são sempre guiados por interesses próprios, sempre buscam aquilo que é o melhor para si mesmos, usando se necessário for, de quaisquer artifícios para a obtenção dos resultados esperados. Para tanto, podem lançar de artifícios diversos (mentira, engano, apropriação indevida, etc.). As condutas oportunistas afetam os custos de transação, questão estudada pela economia, mas regulada pelo direito. Assim, tanto o processo de contratação, quanto a formação de instituições são afetados por esses fenômenos. Os custos de transação, portanto, são entendidos como os "custos da administração do sistema econômico" (Arrow, 1969, p. 48), que são mais altos conforme a fraqueza ou debilidade das instituições na regulação da economia. Entretanto, em economias com instituições sólidas é possível que se alcance bons custos de transação devido à possibilidade de mitigação das condutas oportunistas, e da redução dos efeitos da incerteza. 
Diante dessas afirmações, pode-se sustentar que a TCT está firmada na ideia de que os custos da empresa não dizem respeito unicamente aos custos de produção, mas que também envolvem os custos que os agentes econômicos enfrentam quando interagem no mercado para viabilizar a sua atividade, seja adquirindo equipamentos, serviços, ou outros insumos. Essa interação se dá por intermédio dos contratos entabulados. Portanto, as instituições exercem um papel fundamental, no sentido de oferecer certa estabilidade e contribuírem para minimização dos efeitos da incerteza, por meio do estabelecimento de um ambiente no qual vigora certa previsibilidade, continuidade e confiança, o que é decisivo para o estabelecimento de bons custos de transação.

$\mathrm{Na}$ esfera do direito, historicamente a propriedade tem sido considerada como um direito real, não apenas nos sistemas jurídicos de tradição romano-germânica (Civil Law), como também, nos sistemas da Common Law. Entende-se que essa compreensão do caráter real do direito de propriedade é central para o direito civil, que situa os direitos reais, no "direito das coisas". Merril e Smith (2001), no artigo intitulado "What Happened to Property in Law and Economics?" (“O que Aconteceu com a Propriedade no Direito e na Economia?"), no entanto, se perguntam por que advogados com orientação econômica e economistas anglo-americanos foram abandonando essa ideia. Eles mesmos respondem: por que "essa conversa de uma categoria especial de direitos relacionados com coisas, supostamente ilustraria uma aderência ou devoção servil aos deuses do direito romano". Deve-se considerar, no entanto, que para a Common Law, muito embora os direitos reais, com seus numerus clausus (número fechado) não sejam desconhecidos, eles não têm a mesma importância como nos países da Civil Law (Merril; Smith, 2001).

A expressão latina numerus clausus indica que os direitos reais não podem ser criados livremente, uma vez que a existência destes é limitada pelo rol taxativo previsto em lei, nem o juiz pode reconhecer direitos reais, fora desse rol. Portanto, nos países da jurisdição civil, esse entendimento é bastante pacífico. Ocorre que nos sistemas da Common Law, que conferem ao julgador verdadeira função legislativa, certamente esses conceitos soam estranhos. Muito embora, também na Common Law, o direito de propriedade seja regulado em lei, entende-se que a compreensão do caráter real da propriedade e das suas consequências é vital para a compreensão da propriedade como instituição jurídica e econômica. Isso quer dizer que entender que o direito real de propriedade é uma instituição muito específica, definida em lei em rol restrito, limita as 
possibilidades de se considerar todo e qualquer direito oriundo de transações econômicas como direitos de propriedade (Merril; Smith, 2001).

Assim, para o direito, a concepção tradicional de propriedade está relacionada aos bens corpóreos, ou seja, o direito de propriedade originalmente nasceu como um direito real ${ }^{34}$ sobre bens tangíveis (Gomes, 2008; Ruggiero, 1972). No âmbito dos direitos reais o titular do direito estabelece uma relação direta e imediata com a coisa, e, ao mesmo tempo, uma relação jurídica com a coletividade, indistintamente, já que passa a autorização legal para opor o seu direito erga omnes (contra todos). O sujeito passivo, ou seja, aquele que deve se abster de molestá-lo, é indeterminado e universal, já que se forma uma relação abstrata entre o titular da propriedade e qualquer um que possa, eventualmente, atrapalhar a fruição do direito (Pereira, 1999).

Relação diversa ocorre diante dos direitos pessoais, como os direitos obrigacionais, por exemplo. Nesses casos, a relação jurídica se dá apenas entre as partes efetivamente envolvidas na negociação, ou seja, entre o sujeito ativo (credor) e o sujeito passivo (devedor), em torno de um objeto (coisa). Direitos pessoais, portanto, dizem respeito às relações entre pessoas determinadas que se obrigam a: (i) dar/entregar, (ii) fazer/realizar, ou (iii) deixar de fazer.

No entanto, independentemente do tipo de propriedade, se sobre bens corpóreos ou intelectuais, a propriedade é um direito fundamental do ser humano, conforme dispõe o caput do artigo 5. ${ }^{\circ}$ da Constituição Federal de 1988, e o proprietário, para o Código Civil brasileiro, artigo 1.228 , "tem a faculdade de usar, gozar e dispor da coisa, e o direito de reavê-la do poder de quem quer que injustamente a possua ou detenha" (BRASIL, 2002). ${ }^{35}$ Ocorre, entretanto, que embora a propriedade seja um direito fundamental, considerado absoluto e perpétuo ${ }^{36}$, modernamente o exercício desses direitos é limitado por força de lei. Nesse sentido, na atualidade, o exercício dos direitos de propriedade está vinculado à sua função econômica e social. Portanto, o direito de propriedade que no passado era considerado absoluto e ilimitado em termos de fruição e uso, passa

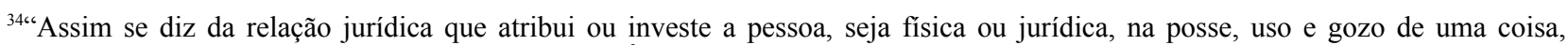
corpórea ou incorpórea, que é da sua propriedade". É uma relação que se dá entre o objeto de direito (a coisa) e o sujeito de direito (o titular: proprietário, possuidor, entre outros) (Silva, 2002, p. 277). Nos direitos reais temos o titular do direito que estabelece uma relação jurídica com a coletividade, indistintamente, ou seja, ele pode opor o seu direito erga omnes (contra todos). Portanto, o sujeito passivo é indeterminado e universal, pois forma-se uma relação "abstrata" entre o titular da propriedade e qualquer um que possa, eventualmente, contestá-la (Pereira, 1999). Nos direitos pessoais, direitos creditícios, por exemplo, a relação jurídica se dá apenas entre as partes efetivamente envolvidas na negociação, ou seja, entre o sujeito ativo (credor) e o sujeito passivo (devedor), em torno de um objeto (coisa).

${ }^{35}$ Disponível em: <http://www.planalto.gov.br/ccivil_03/leis/2002/L10406.htm>. Acesso em: 25 ago. 2015.

${ }^{36} \mathrm{O}$ direito real de propriedade é considerado absoluto porque, além de ser oponível contra todos, dá ao seu titular o poder de decidir como irá utilizar, frui ou dispor do bem. É perpétuo porque não tem duração limitada no tempo e a sua utilização não implica no esgotamento do direito.
} 
a ser relativizado, tendo em vista o interesse da coletividade, visto que o exercício abusivo de direitos é coibido pelo direito. $\mathrm{O}$ abuso de direito ocorre quando aquele que, tendo várias possibilidades de exercitar o seu direito, escolhe a mais danosa, praticando ato ilícito.

A repressão ao exercício abusivo de direitos é uma novidade introduzida pelo novo Código Civil de 2002 que, em seu artigo 187, estabelece que tal prática configura-se ato ilícito. Também existem regras em legislação especial que disciplinam os crimes contra a ordem econômica (legislação antitruste), quando em detrimento do direito constitucional da livre concorrência e da livre iniciativa, os concorrentes agem de forma oportunista. Um exemplo disso pode ser encontrado, por exemplo, na Lei 9.279/96, Lei da Propriedade Industrial, que em seu artigo 68 dispõe que "o titular ficará sujeito a ter a patente licenciada compulsoriamente se exercer os direitos dela decorrentes de forma abusiva, ou por meio dela praticar abuso de poder econômico, comprovado nos termos da lei, por decisão administrativa ou judicial" (Brasil, 1996, grifo nosso). ${ }^{37}$

Diante dessa perspectiva, o arcabouço legal, com o seu conjunto de institutos e de restrições legais, visa proporcionar estabilidade social diante da possibilidade do uso nocivo da propriedade e de condutas oportunistas, conforme é possível depreender dos parágrafos $1^{\circ}$, e seguintes, do artigo 1.228 do Código Civil:

$\S 1^{\circ} \mathrm{O}$ direito de propriedade deve ser exercido em consonância com as suas finalidades econômicas e sociais e de modo que sejam preservados, de conformidade com o estabelecido em lei especial, a flora, a fauna, as belezas naturais, o equilíbrio ecológico e o patrimônio histórico e artístico, bem como evitada a poluição do ar e das águas.

$\S 2^{\circ}$ São defesos os atos que não trazem ao proprietário qualquer comodidade, ou utilidade, e sejam animados pela intenção de prejudicar outrem.

§ 3. O proprietário pode ser privado da coisa, nos casos de desapropriação, por necessidade ou utilidade pública ou interesse social, bem como no de requisição, em caso de perigo público iminente (BRASIL, 2002). ${ }^{38}$

Logicamente que os dispositivos do Código Civil citados acima dizem respeito aos direitos sobre bens corpóreos, em especial, sobre a propriedade imóvel. Entretanto, é sabido que a propriedade tanto poderá se originar de um bem corpóreo, quanto incorpóreo, e, por esse motivo, entende-se que é possível aplicar as restrições e princípios acima mencionados também à propriedade intelectual. Gomes (2008, p. 112), no entanto, não entende dessa maneira. Segundo o autor:

\footnotetext{
${ }^{37}$ Disponível em: <http://www.planalto.gov.br/ccivil_03/Leis/L9279.htm>. Acesso em: 25 ago. 2015.

${ }^{38}$ Disponível em: < http://www.planalto.gov.br/ccivil_03/leis/2002/L10406.htm>. Acesso em: 25 ago. 2015.
} 
O fenômeno da propriedade incorpórea explica-se como reflexo do valor psicológico da ideia de propriedade, mas, embora esses direitos novos tenham semelhança com o de propriedade porque são exclusivos e absolutos, com ela não se confundem. A assimilação é tecnicamente falsa. Poderiam enquadra-se, contudo, numa categoria à parte, que, alhures, denominamos quase - propriedade.

Barbosa (2003, p. 69) argumenta que as patentes, os direitos autorais e as marcas também são direitos "absolutos", exclusivos e de caráter patrimonial e indaga: "onde encontraremos normas relativas a figuras jurídicas similares, senão nas disposições referentes aos direitos reais?”. Dessa forma, os direitos reais passaram a servir de paradigmas para os direitos da propriedade intelectual, tendo em vista a inexistência de regras específicas para regular o assunto. Assim, ao defender que as regras aplicáveis às coisas tangíveis também poderiam ser utilizadas, ao menos em grande parte, às atividades humanas, o autor realiza essa atividade interpretativa em busca do dispositivo legal mais adequado ao tratamento da questão (Barbosa, 2003). Para a diferenciação entre bens tangíveis e intangíveis Barbosa (2009, p. 11) explica o seguinte:

\begin{abstract}
Uma vez que se distinguem os bens intangíveis, ou incorpóreos, dos bens tangíveis perante os quais reagem os sentidos, é necessário reencontrar essa distinção no livro de papel ou pergaminho e a poesia, elocução ou imagem visual que nele se encerra. $\mathrm{O}$ bem incorpóreo subsiste, muitas vezes, além de qualquer suporte, mas pode habitar o livro, máquina ou planta. Tal distinção entre o corpóreo (a que se dá o nome de corpus mechanicum) e o bem imaterial (a que se dá o nome de corpus mysticum) tem enormes consequências para o direito.
\end{abstract}

Assim sendo, considerando que a propriedade sobre bens intangíveis também deverá obedecer à sua função social, entende-se que, pelo fato de representarem direitos que são limitados pelas suas funções. Logo, as patentes, que são um tipo específico de propriedade intelectual (propriedade industrial), por exemplo, também representam formas de uso social da propriedade, ou seja, são direitos que existem enquanto forem socialmente úteis. Além disso, a temporariedade do direito passa a ser considerada como um "elemento crucial do equilíbrio de interesses" (Barbosa, 2003, p. 368). Dessa forma, não apenas a tecnologia será divulgada e conhecida por intermédio da publicação da patente, como também o seu uso passará a ser acessível por todos, após o decurso do prazo legal de proteção, 20 anos para as patentes de invenção. No entanto, é importante considerar a exigência do uso adequado do privilégio de exclusividade conferido pela patente.

Por tratar-se de um mecanismo que restringe a liberdade de concorrência, a utilização da patente deverá observar a finalidade desse instituto. Isso quer dizer que a utilização do direito à exclusividade que esteja em desacordo com tal finalidade é contrária ao direito posto. Essas 
limitações indicam que também a propriedade sobre bens intangíveis deverá ser utilizada conforme a sua utilidade econômica e social (Barbosa, 2003). No artigo $2^{\circ}$ da Lei de Propriedade Industrial (9.279/96) está disposto que a proteção leva em consideração o interesse social desses direitos e o desenvolvimento tecnológico e econômico nacional. O interesse social está, não apenas na ampliação do conhecimento, mas também, nos benefícios que os inventos podem propiciar à sociedade (avanços na área da saúde, da agricultura, entre outras).

Assim sendo, entende-se que a "a instituição dos direitos de propriedade coordena as expectativas dos indivíduos com o objetivo de impedir conflitos custosos, incerteza e ausência de incentivos para investimentos e inovação" (Mendes, 2006, p. 15). Nesse contexto, a função dos direitos de propriedade é de estabelecer os limites e o alcance do exercício aos seus detentores. Dentro dessa extensão e alcance encontramos as seguintes possibilidades: a possibilidade de uso e transformação do ativo; a possibilidade de obtenção de rendas oriundas da exploração do ativo; a cessão do ativo a um terceiro seja ela gratuita ou onerosa (Mendes, 2006).

Sherwood (1992, p. 16) entende que "o sistema de proteção à propriedade intelectual pode ser considerado como uma parte valiosa da infraestrutura de um país". Isso quer dizer que a existência de um sistema de propriedade intelectual que forneça proteção às inovações e às expressões criativas pode ser visto como condição prévia para a concepção e o uso de novas tecnologias, o que pode promover crescimento econômico e auxiliar no desenvolvimento. Esse autor entende que muito embora a proteção à propriedade intelectual seja imperfeita, ela funciona. Assim sendo, embora uma patente não consiga assegurar o sucesso comercial, ou a suplantação da invenção pelos concorrentes, o direito de exclusividade temporária, na exploração do invento, encoraja que este torne público os seus inventos (Sherwood, 1992).

Dessa forma, o papel dos direitos de propriedade no âmbito dos bens intangíveis, como é o caso dos bens oriundos do conhecimento é complexo, uma vez que tais bens têm todas as características de bens públicos, ou seja, não rivais e não exclusivos. A combinação dessas duas características cria problemas de apropriabilidade. A não-rivalidade indica que o bem pode ser consumido por diversos indivíduos sem que perca a sua utilidade. Essa característica permite uma rápida dispersão do conhecimento, pois cada usuário pode usar e reutilizar, ou seja, copiar e recopiar a informação perpetuamente, sem que ela se esgote. A não-exclusividade está relacionada com a impossibilidade de se excluir terceiros da utilização desse bem. O conhecimento, portanto, sendo dotado dessas características, tende a ser exposto e divulgado em círculos cada vez maiores 
(Even, 2009).

Devido à impossibilidade de exclusão, a apropriabilidade dos bens intangíveis é dificultada visto que as ideias tecnológicas podem ser utilizadas por muitas pessoas, em benefício próprio e em concorrência direta com o autor destas, sem que se pague por elas. Ocorre que ante a possibilidade de ser facilmente imitado, um produtor não se sentiria incentivado a alocar recursos e engenhosidade no desenvolvimento de invenções. Então, a questão da apropriabilidade passar a ser reconhecida como a pedra angular dos regimes de propriedade intelectual (Even, 2009).

Assim sendo, entende-se que a importância da proteção à propriedade intelectual como mecanismo de garantia dos direitos e de estímulo aos investimentos tem crescido em decorrência dos seguintes fatores: (i) da intensificação do desenvolvimento científico e tecnológico; (ii) da aproximação da ciência com o mercado; (iii) da redução dramática do tempo requerido para o desenvolvimento tecnológico e para a incorporação dos resultados ao processo produtivo; (iv) da redução do ciclo de vida dos produtos; (v) do aumento dos custos de P\&D e dos riscos que envolvem a opção tecnológica; (vi) da incorporação da inovação como elemento de ampliação da competitividade; (vii) da capacidade de codificação dos conhecimentos (Buainain; Carvalho, 2000).

\section{Considerações finais}

O estudo permitiu concluir que os conceitos de instituição para o direito e para a economia são convergentes, embora seja mais aberto para a Nova Economia Institucional (NEI), aqui representada por Douglas North, que considera as regras informais como as tradições, costumes, também como instituições, e mais "fechado" para o institucionalismo (jurídico) clássico. Mesmo assim, é possível perceber, que o entendimento comum, em síntese, concebe as instituições como realidades que suportam, restringem, asseguram, viabilizam e estruturam a convivência social. Conforme mencionado, não é possível realizar uma "tradução" literal dos conceitos jurídico e econômico de direito de propriedade, pois a economia inclui tanto os direitos reais quanto os obrigacionais nesse rol.

Sejam vistas como fatos institucionais, como sistemas de incentivos ao desenvolvimento econômico, como as regras do jogo, restrições, normas, sejam, portanto, "instituições-coisas”, ou 
“instituições-pessoas”, o fato é que as instituições são essenciais tanto ao direito, quanto à economia e esses dois campos estão completamente interrelacionados.

O estabelecimento dos direitos de propriedade, a formação dos contratos e a solidez das instituições (num sentido amplo) são essenciais para a redução dos efeitos da incerteza e fatores essenciais para definição de bons custos de transação. Os direitos de propriedade, numa economia capitalista, permitirem ao proprietário o planejamento de ações futuras, tais como, a definição de metas e de estratégias para a alocação de recursos financeiros, para a realização de parcerias, a possibilidade de transferência de direitos, entre outras, podendo inclusive lançar mão de medidas legais para coibir condutas desleais e oportunistas.

Especialmente quando estão envolvidos direitos que se originaram de um tipo de propriedade muito específica, a propriedade intelectual, ou seja, direitos nascidos de um bem considerado intangível, como é o caso do conhecimento, a questão da apropriação privada torna-se muito mais crítica devido à sua natureza de bem público, conforme já mencionado. A nãorivalidade e a não-exclusividade podem dificultar a apropriação econômica, mesmo na existência da apropriação jurídica (o título de propriedade). Isso simplesmente quer dizer que o conhecimento pode ser reproduzido inúmeras vezes, causando empecilhos à fruição econômica do seu titular.

Sendo assim, os direitos da propriedade intelectual (DPIs), podem ser vistos como institutos, instituições, fatos institucionais, que excluem terceiros da exploração enquanto o objeto da proteção não tiver "caído" em domínio público. São direitos que garantem a apropriação jurídica, possibilitando a definição de estratégias para a apropriação econômica.

No entanto, o impacto dos DPIs dependerá do contexto institucional, o que implica que em sistemas fortes de propriedade intelectual, as regras evoluem em paralelo com a evolução do sistema jurídico, com o sistema de mercado e com as normas culturais (a criação de uma cultura de valorização da criatividade e da proteção aos direitos que dela decorrem) e isso depende também das políticas educacionais. Além disso, os DPIs também precisam ser avaliados dentro de um contexto político mais amplo que inclui políticas de comércio exterior, de concorrência, entre outras, e a solidez das instituições é essencial nesse processo.

\section{Referências Bibliográficas}

ARROW, Kenneth J. The organization of economic activity: issues pertinent to the choice of market versus non market allocation. In: The Analysis and Evaluation of Public Expenditures: The PPB System - a compendium of papers submitted to the Subcommittee on Economy in Government of the 
joint Economic Committee Congress of the United States. Washington, D.C., Government Printing Office, Washington, v., p. 47-64, 1969.

ARIDA, P. A. Pesquisa em Direito e Economia: em torno da historicidade da norma. In Revista Direito GV, v. 1, n. 1, p. 11-22, maio 2005.

BARBOSA, D. B. Do Bem Incorpóreo à Propriedade Intelectual. 2009. Disponível em: $<$ www.denisbarbosa.addr.com/arquivos/novidades/teoria.pdf $>$. Acesso em 12 jun. 2015.

. Uma Introdução à Propriedade Intelectual. 2. ed. Rio de Janeiro: Lumen Juris, 2003.

BOBBIO, Norberto. O Positivismo Jurídico: lições de filosofia do direito. São Paulo: Ícone, 2006.

BRASIL. Lei $\mathrm{n}^{\circ}$ 10.406, de 10 de Janeiro de 2002. Institui o Código Civil. Disponível em: $<$ http://www.planalto.gov.br/ccivil_03/leis/2002/L10406.htm>. Acesso em: 25 ago. 2015.

. Lei $\mathrm{n}^{\circ}$ 9.279, de 14 de Maio de 1996. Regula direitos e obrigações relativos à propriedade industrial.Disponível em: $<$ http://www.planalto.gov.br/ccivil_03/Leis/L9279.ht m>. Acesso em: 25 ago. 2015.

BUAINAIN, A. M. e CARVALHO, S. M. P. Propriedade Intelectual em mundo globalizado Parcerias Estratégicas, Brasília, n.9, p.145-153, 2000.

CASAL, J. M. La investigación en historia de las instituciones y lafunción de lasideas. Revista de la Facultad de Derecho, Montevideo, v.5, p.: 57 - 65, 1993.

CHAVES, P. R. L. Direitos de propriedade e desmatamento na velha e na nova fronteira agrícola: o caso dos estados do Paraná e do Pará. 2008. Dissertação (MestradoemDesenvolvimentoEconômico) - Universidade Federal do Paraná.

DEMSETZ, H. Toward a theory of propertyrights, American EconomicReview, v. 57, n. 2, p. 347359, 1967.

ESTEVES, H. L. B.; MELLO, M. T. L.Direito e Economia nanoção de 'direitos de propriedade'. Disponível em: $<$ http://www.ie.ufrj.br/datacenterie/pdfs/seminarios/pesquisa/t exto1111.pdf>. Acesso: 12 nov. 2014.

EVEN, Y. Appropriability and Property. American University Law Review, Washington, v. 58, n. 6, p. 1417-1476, Jul. 26, 2009.

GOMES, O. Direitos Reais. 19. ed. Rio de Janeiro: Forense, 2008.

HARDIN, G. The Tragedy of the Commons, Science, v.162, p. 1243-1248, Dec. 1968.

HAURIOU, M. La Teoria de la Institucion y de la Fundacion: ensayo de vitalismo social.Traducción del francés, prólogo y bibliografía del autor por Arturo Enrique Sampay. Buenos Aires, Abeledo-Perrot, 1968. 
HOBBES, T. Leviathan or the Matter, Forme, \& Power of a Common-wealth Ecclesiasticall and Civill. London: Andrew Crooke, 1651. Disponível em: $<$ http://socserv2.s

ocsci.mcmaster.ca/econ/ugcm/3113/hobbes/Leviathan.pdf>. Acesso em: 30 ago. 2015.

JACQUEMIM, A.; SCHRANS, G. O Direito Económico. Lisboa: Vega, 1979.

LA TORRE, M. Law and Philosophy Library, Dordrecht Heidelberg, London, New York: Springer, v. 90, part. 2, p. 97-134, 2010.

- Teorías institucionalistas del Derecho: esbozo de una voz de enciclopédia. Derechos y libertades: Revista del Instituto Bartolomé de las Casas, Madrid, ano 10, n. 14, p. 103112, 2006. Law as Institution

LIBECAP, Gary D. Contracting for Property Rights. Cambridge: Cambridge University Press, 1989.

LUECK, D. MICELI, T. J. Property Law. In: POLINSKY, A. M.; SHAVELL, S. (Eds.). Handbook of Law and Economics. Amsterdam and Oxford: North-Holland, 2007, p. 186-257

MACCORMICK, Neil. Norms, Institutions, and Institutional Facts. Law and Philosophy, Netherlands: Springer, v. 17, n. 3, p. 301-345, May 01, 1998.

MATTHEWS. R. C. O. The Economics of Institutions and the Sources of Growth. The Economic Journal,v. 96, n. 384, p. 903-918, dec., 1986.

MELLO, M. T. L. Propriedade Intelectual e Concorrência. Revista Brasileira de Inovação, Rio de Janeiro, n. 8, v. 2, p.371-402, jul./dez. 2009.

MENDES, C. I. C. Software livre e inovação tecnológica: uma análise sob a perspectiva da propriedade intelectual. Dissertação (Mestrado Desenvolvimento Econômico, Espaço e Meio Ambiente) - Universidade Estadual de Campinas. Instituto de Economia, Campinas, SP: [s.n.], 2006.

MERRIL, T. \& SMITH, H. What Happened to Property in Law and Economics? The Yale Law Journal,v. 111, p. 357-398, 2001.

NOBRE, M. Apontamentos sobre a pesquisa em Direito no Brasil. Novos Estudos, CEBRAP, n. 66, p. 145-154, jul. 2003.

NORTH, D.C., "Institutions". Journal of Economic Perspectives, v. 5, n. 1, p. 97-112, 1991.

PEREIRA, C. M. da S. Instituições de Direito Civil: posse, propriedade, direitos reais de fruição, garantia e aquisição. 13. ed. Rio de Janeiro: ForenseUniversitária, 1999. v. 4.

REALE, M. Lições Preliminares de Direito. 27 ed. São Paulo: Saraiva, 2009. . Fundamentos do Direito. 2 ed. rev. São Paulo: Revista dos Tribunais, 1972.

SHERWOOD, R. M. Propriedade Intelectual e Desenvolvimento Econômico. São Paulo: EDUSP. 